\title{
High Ultrafiltration Increasing Intradialytic Blood Pressure on Hemodialysis Patients
}

\author{
Yunie Armiyati1,2, Suharyo Hadisaputro ${ }^{3}$, Shofa Chasani ${ }^{4,5}$, Untung Sujianto ${ }^{6}$
}

1 Department of Nursing, Universitas Muhammadiyah Semarang, Indonesia

Doctoral Program, Faculty of Medicine, Universitas Diponegoro, Indonesia

Postgraduate Program of Health Polytechnic of Semarang

Hemodialysis Center, Roemani Hospital, Indonesia

Faculty of Medicine, Universitas Muhammadiyah Semarang, Indonesia

Department of Nursing, Faculty of Medicine, Universitas Diponegoro, Indonesia

\section{Article Info}

Article History:
Submit Feb 20th, 2021
Accepted March 16th, 2021
Published March 28th 2021
Keywords:
Hemodialysis;
Ultrafiltration; Intradialytic
blood pressure

\section{INTRODUCTION}

Chronic Kidney Disease (CKD) is an irreversible decline in renal function so that the kidneys are unable to regulate body homeostasis. ${ }^{1}$ CKD patients at the End Stage Kidney Disease stage require renal replacement therapy to maintain body functions. $^{2}$ Hemodialysis is a kidney

\section{Abstract}

The increase in blood pressure when the patient is undergoing hemodialysis is experienced by patients with intradialytic hypertension. This condition can be very dangerous for the patient, must be prevented and needs to be controlled. Prevention can be done by controlling variables that can affect intradialytic blood pressure, including ultrafiltration during hemodialysis. This study aims to analyze the relationship between ultrafiltration (ultrafiltration goal, ultrafiltration rate) and intradialytic blood pressure. This research was a descriptive-analytic study with a cross-sectional design, with 112 samples at two centres of dialysis in Semarang. Data were analyzed using the Spearman Rho. The finding obtained showed that ultrafiltration goal (UFG) and ultrafiltration rate (UFR) correlated with intradialytic blood pressure (systolic, diastolic and mean arterial pressure). The magnitude of UFG an associated with increase in intradialytic systolic $(p=0,024 ; r=0,213)$, increase in intradialytic diastolic $(p=0,007 ; \mathrm{r}=0,252)$ and increase in mean arterial pressure $(\mathrm{p}=0,016 ; \mathrm{r}=0,227)$. High UFR is associated with with increase in intradialytic systolic $(p=0,037 ; r=0,211)$, increase in intradialytic diastolic $(p=0,001 ; r=0,320)$ and increase in mean arterial pressure $(p=0,034 ; r=0,200)$. Determination of ultrafiltration during hemodialysis must be done carefully and precisely to prevent an increase in intradialytic blood pressure.

Corresponding author:

Yunie Armiyati

yunie@unimus.ac.id

South East Asia Nursing Research, Vol 3 No 1, March 2021

ISSN:2685-032X

DOI: https://doi.org/10.26714/seanr.3.1.2021.8-15

replacement therapy that is widely used by patients with end-stage kidney disease.

Hemodialysis is effective in removing fluids, electrolytes and metabolic waste and improves the quality of life for CKD patients. The main goal of hemodialysis in patients with End-Stage Kidney Disease is symptom relief, controlling uremia, fluid overload, 
and electrolyte imbalance. ${ }^{3}$ However, various intradialytic complications can occur in patients undergoing hemodialysis. The complications experienced by many hemodialysis patients are an increase in intradialytic blood pressure or the occurrence of intradialytic hypertension. Intradialytic hypertension is a persistent increase in blood pressure during hemodialysis and at the end of hemodialysis is higher than blood pressure at the initiation of hemodialysis. It's marked by an increase in Mean Arterial Blood Pressure (MAP) > $15 \mathrm{mmHg}$ on dialysis sessions.

Several studies in Indonesia show that the incidence of intradialytic hypertension is a common complication experienced by many patients. A retrospective cohort study of 22,955 hemodialysis treatments showed that the prevalence of intradialytic hypertension was 21.3 per 100 procedures. ${ }^{4}$ Research in Denpasar found that the incidence of IDH was $32.1 \% .^{5}$ Research on hemodialysis patients in Yogyakarta also concluded that the frequency of intradialytic hypertension was 54\%. ${ }^{6}$ Another study on 198 hemodialysis patients in Palembang also showed that $58.6 \%$ of the patients had intradialytic hypertension. The increase in blood pressure can be severe even to the point of a hypertensive crisis that endangers the patient. ${ }^{7}$

High intradialytic blood pressure will affect hemodialysis adequacy, increasing the risk of heart failure and patient death. Previous studies in 151 routine hemodialysis patients showed that high interdialytic blood pressure was associated with an increased risk of stroke and death. A total of $13.91 \%$ of patients with high interdialytic blood pressure had a stroke and $16.56 \%$ of patients died. ${ }^{8}$ An increase in intradialytic blood pressure must be anticipated with proper control of the risk factors.

Various factors cause an increase in intradialytic blood pressure including excess fluid (fluid overload). An increase in blood pressure during hemodialysis can occur due to activation of the reninangiotensin-aldosterone system (RAAS) due to hypovolemia when the fluid withdrawal is carried out through Ultrafiltration. ${ }^{7}$ The process of withdrawal of fluid during hemodialysis through Ultrafiltration involves the fluid withdrawal rate or ultrafiltration rate (UFR) and the amount of fluid withdrawn or ultrafiltration goal (UFG). The amount and speed of fluid withdrawal during hemodialysis can be seen from the ultrafiltration which is regulated in the form of UFG and UFR determination.

Determination of the UFG and UFR should be optimal to achieve normotensive conditions in hemodialysis patients. When hemodialysis is performed, the UFG determination is determined to draw excess fluid in the blood, the UFG size depends on the addition of the interdialytic body weight gain (IDWG) and the target patient's dry weight. ${ }^{9}$ The phenomenon in the field is often the determination of ultrafiltration based on the increase of IDWG which indicates the amount of fluid buildup in the body. Excess fluid occurs due to poor fluid intake regulation during the interdialytic period, which is characterized by a high IDWG value. ${ }^{10}$ If fluid intake is excessive, during the period between dialysis there will be a large weight gain. ${ }^{11}$

Hypervolemia (fluid overload) is believed to play a role in the pathogenesis of intradialytic hypertension. ${ }^{12}$ Often the ultrafiltration determination during hemodialysis exceeds the requirements. A decrease in relative blood volume and total blood volume due to a large ultrafiltration goal decreases blood flow to the kidneys, stimulates the release of renin and causes hypertension. ${ }^{13}$

This study aims to analyze the relationship between ultrafiltration during hemodialysis (ultrafiltration goal, ultrafiltration rate) and intradialytic blood pressure. This research is useful to anticipate and prevent 
intradialytic hypertension by controlling these factors.

\section{METHODS}

The study design was a cross-sectional study. The aim of the studies to determine the relationship between ultrafiltration goal (UFG), ultrafiltration rate (UFR) and intradialytic blood pressure. The population were 188 patients who underwent hemodialysis in January 2019 in two hemodialysis units in Semarang Central Java, Indonesia. Sampling using purposive sampling according to the inclusion criteria. The inclusion criteria of this study were: patients undergoing regular hemodialysis for more than three months, scheduled hemodialysis with a frequency of 2 times a week with a duration of hemodialysis 4 hours, awareness of compos mentis, can communicate well verbally, aged $18-60$ years and not using erythropoietin. The sample of this study were 112 patients.

The instrument used in this study as a tool for measuring blood pressure (BP) before, during and after the patient underwent hemodialysis using a digital sphygmomanometer. Measurement blood pressure using a standard digital sphygmomanometer that has been calibrated. Blood pressure measurements were taken before hemodialysis, at 2.5 hours hemodialysis (intradialytic) and after hemodialysis. Measurements were made on the arm that was not attached to the vascular access. The predialysis blood pressure was measured 5 minutes before the dialysis needle was inserted and the post-analysis blood pressure was measured 5 minutes after the dialysis needle was removed. UFG is the amount of fluid drawn by the hemodialysis machine during a hemodialysis session in litres, which can be seen from the hemodialysis machine monitor screen. Excess UFG is the amount of fluid drawn by the hemodialysis machine during one HD session in excess of $4.8 \%$ dry body weight. UFR is the amount of fluid drawn by the hemodialysis machine per kilogram of body weight per hour (ml/kg/hour).

This research applies the principles of research ethics include the principles of confidentiality, benefits, the principles of respecting human dignity and the principles of justice. This study was conducted after obtaining approval from the ethics committee. The principles of research ethics in this research.

Univariate analysis was used to describe the characteristic data of respondents in the form of age, gender, frequency of hemodialysis, length of undergoing hemodialysis, and ultrafiltration (UFG and UFR). Research data were analyzed univariately and using a personal computer program. Univariate analysis by presenting numeric and categorical data. Numerical data such as age, frequency of hemodialysis, length of undergoing hemodialysis, ultrafiltration (UFG and UFR) and blood pressure are described in the central tendency (mean, minimum, maximum and standard deviation). Data categorized by gender distributed in a frequency distribution. The data normality test was carried out before carrying out the bivariate test. The results of the normality test with Saphiro Will showed that ultrafiltration data and intradialytic blood pressure were not normally distributed ( $p<0.005)$. Bivariate analysis was performed using statistical data processing software on the computer, used Spearman's rho test. Bivariate statistical test to determine the relationship and direction of the relationship between the ultrafiltration variable and intradialytic blood pressure.

\section{RESULTS}

Table 1 showed the mean patient age was 47,77 years with the youngest age being 20 years and the oldest being 70 years. The number of male and female respondents is equal, each $50 \%$. The mean length of hemodialysis was 26,20 months. The mean frequency of hemodialysis was 184,95 times. The mean of ultrafiltration goal (UFG) was 
2704,91 times and the mean of ultrafiltration goal (UFR) was 11,366 $\mathrm{mL} / \mathrm{h} / \mathrm{kg}$.

The results in table 2 show that the mean pre-dialysis systolic blood pressure was $158.214 \mathrm{mmHg}$, the lowest was 107 $\mathrm{mmHg}$ and the highest was $195 \mathrm{mmHg}$. The mean pre-dialysis diastolic blood pressure was $86.652 \mathrm{mmHg}$, the lowest was $76 \mathrm{mmHg}$ and the highest was 114 mmHg. The mean intra-dialysis systolic blood pressure was $168.839 \mathrm{mmHg}$, the lowest was $110 \mathrm{mmHg}$ and the highest was $198 \mathrm{mmHg}$. The average intradialysis diastolic blood pressure was $95.161 \mathrm{mmHg}$, the lowest was $86 \mathrm{mmHg}$ and the highest was $115 \mathrm{mmHg}$. The average post-dialysis systolic blood pressure was $169.920 \mathrm{mmHg}$, the lowest was $100 \mathrm{mmHg}$ and the highest was 211 mmHg. The mean post-dialysis diastolic

Table 1

Characteristic of respondents $(n=112)$

\begin{tabular}{lccc}
\hline \multicolumn{1}{c}{ Indicators } & f & $\mathbf{\%}$ & Mean \pm SD (min-max) \\
\hline Age & & & $47,77 \pm 11,66(20-70)$ \\
Gender & 56 & 50 & \\
$\quad$ Male & 56 & 50 & \\
$\quad$ Female & & & $184,95 \pm 153,79(24-807)$ \\
Frequency of hemodialysis & & & $26,20 \pm 39,012(3-374)$ \\
Length of hemodialysis (months) & & & $2704,91 \pm 1000,359(500-4000)$ \\
Ultrafiltration Goal (ml) & & & $11,366 \pm 4,020(2-18)$ \\
Ultrafiltration Rate (mL/h/kg) & & \\
\hline
\end{tabular}

Table 2

Description of Pre, Intra dan Post Hemodialysis Blood Pressure ( $\mathrm{n}=112)$

\begin{tabular}{lc}
\hline \multicolumn{1}{c}{ Indicators (Blood Pressure) } & Mean \pm SD (min-max) \\
\hline Pre dialytic blood pressure & \\
Sistolic $(\mathrm{mmHg})$ & $158,214 \pm 17,151(107-195)$ \\
Diastolic $(\mathrm{mmHg})$ & $86,652 \pm 18,186(76-114)$ \\
Mean Arterial Pressure $(\mathrm{mmHg})$ & $134,432 \pm 12,736(92,7-164,3)$ \\
Intra dialytic blood pressure & \\
Sistolic ( $\mathrm{mmHg})$ & $168,839 \pm 18,009(110-198)$ \\
Diastolic $(\mathrm{mmHg})$ & $95,161 \pm 9,28(86-115)$ \\
Mean Arterial Pressure $(\mathrm{mmHg})$ & $156,779 \pm 134,049(96,7-155)$ \\
Post dialytic blood pressure & \\
Sistolic (mmHg) & $169,920 \pm 21,461(100-211)$ \\
Diastolic $(\mathrm{mmHg})$ & $94,384 \pm 13,052(74-121)$ \\
Mean Arterial Pressure $(\mathrm{mmHg})$ & $144,763 \pm 17,362(90-174)$ \\
\hline
\end{tabular}

blood pressure was $94.384 \mathrm{mmHg}$, the lowest was $74 \mathrm{mmHg}$ and the highest was $121 \mathrm{mmHg}$.

The figure 1 shows an increase in intradialytic and post-dialysis blood pressure. This research showed that the mean systolic, diastolic and mean arterial pressures of intradialytic and postdialysis were higher than before (pre) hemodialysis.

The results of statistical analysis with Spearman Rho test showed that there was a relationship between ultrafiltration (UFG and UFR) with intradialytic systolic blood pressure, intradialytic diastolic blood pressure $(\mathrm{p}=$ and mean intradialytic arterial pressure ( $p$-value $<0,005)$. The greater the UFG and UFR the higher the intradialytic blood pressure (r 0,211-0,320). 


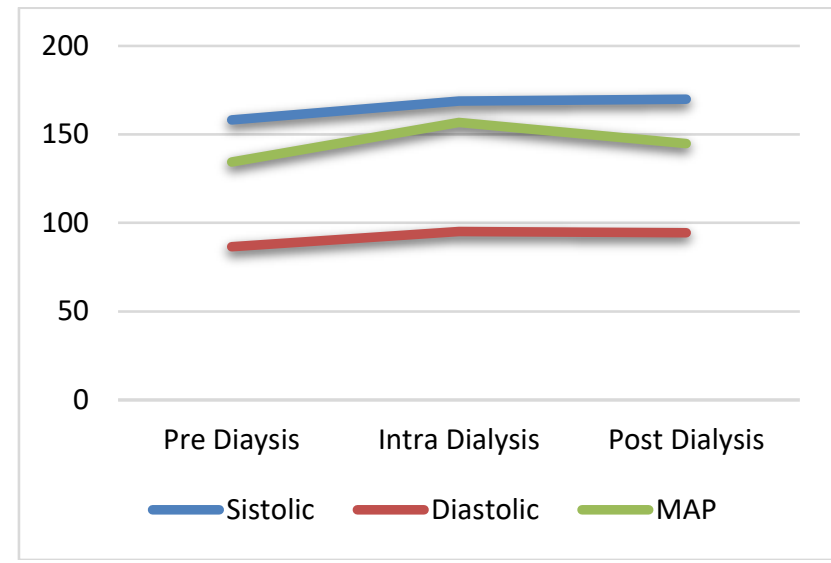

Figure 1

Pre, Intra and Post Hemodialysis Blood Pressure $(n=112)$

Table 3

Statistical analysis of the relationship between ultrafiltration and intradialytic blood pressure in hemodialysis patients $(n=112)$

\begin{tabular}{lcc}
\hline \multicolumn{1}{c}{ Indicators } & $\boldsymbol{p}$ & $\mathbf{r}$ \\
\hline $\begin{array}{l}\text { UFG - Intradialytic Systolic Blood } \\
\text { Pressure }\end{array}$ & $0,024^{*}$ & 0,213 \\
$\begin{array}{l}\text { UFG - Intradialytic Diastolic Blood } \\
\text { Pressure }\end{array}$ & $0,007^{*}$ & 0,252 \\
$\begin{array}{l}\text { UFG - Intradialytic Mean Arterial } \\
\text { Pressure Pressure }\end{array}$ & $0,016^{*}$ & 0,227 \\
$\begin{array}{l}\text { UFR - Intradialytic Systolic Blood } \\
\text { Pressure }\end{array}$ & $0,037^{*}$ & 0,211 \\
$\begin{array}{l}\text { UFR - Intradialytic Diastolic Blood } \\
\text { Pressure }\end{array}$ & $0,001^{*}$ & 0,320 \\
$\begin{array}{l}\text { UFR - Intradialytic Mean Arterial } \\
\text { Pressure (MAP) }\end{array}$ & $0,034^{*}$ & 0,200 \\
\hline *Spearman Rho & & \\
\hline
\end{tabular}

\section{DISCUSSION}

Blood pressure is one hemodynamic indicator that needs to be considered in patients undergoing hemodialysis. An increase in blood pressure or a decrease in blood pressure during the hemodialysis process can endanger the patient's condition. Research on hemodialysis patients in Indonesia shows that the increase in blood pressure during hemodialysis is more experienced by patients undergoing hemodialysis. This research showed that the mean systolic, diastolic and mean arterial pressures of intradialytic and post-dialysis were higher than before (pre) hemodialysis.

The increase in blood pressure during hemodialysis is also referred to as intradialytic hypertension have an increased mortality risk compared to patients with modest decreases in blood pressure during dialysis. Intradialytic hypertension is associated with extracellular volume overload in addition to acute increases in vascular resistance during dialysis. Management strategies should include reevaluation of fluid overload and high ultrafiltration during hemodialysis. ${ }^{14}$ Hemodialysis patients have to control fluid overload by controlling interdialytic weight gain (IDWG).

Control of IDWG is needed to prevent an increase in the incidence of increasing blood pressure during hemodialysis. A study in China showed that reducing fluid overload in intradialytic hypertension patients with high predialytic blood pressure can effectively improve their blood pressure, but did not affect blood pressure in normal predialytic blood pressure intradialytic hypertension cases. ${ }^{15}$

An important factor causing an increase in intradialytic blood pressure, among others, is excess fluid. Hypervolemia condition will have implications for the many intradialytic fluid withdrawals determined by ultrafiltration. Increased blood pressure during hemodialysis can occur due to activation of the renin-angiotensinaldosterone system due to hypovolemia when fluid withdrawal occurs intradialytic through ultrafiltration.

The findings of this study showed that increased ultrafiltration during hemodialysis increases the risk of intradialytic hypertension. This research showed there was a relationship between ultrafiltration (UFG and UFR) with intradialytic systolic blood pressure, intradialytic diastolic blood pressure and intradialytic mean arterial pressure. The greater the UFG and UFR the higher the intradialytic blood pressure.

The results of this study corroborate the findings of previous studies. The findings of 
this study reinforce the results of research on hemodialysis patients in Surakarta, that the amount of ultrafiltration during hemodialysis has a positive correlation with the incidence of increased intradialytic blood pressure with $\mathrm{p}=0.003$ and $\mathrm{r}=$ 0.421 .16 Previous studies have examined ultrafiltration rates for mortality and cardiovascular disease (CVD). Ultrafiltration speed is divided into 3 categories: $\quad<10 \mathrm{ml} / \mathrm{hour} / \mathrm{kg}, \quad 10-13$ $\mathrm{ml} /$ hour $/ \mathrm{kg}$, and $>13 \mathrm{ml} /$ hour $/ \mathrm{kg}$. Faster ultrafiltration in hemodialysis patients is associated with a greater risk of multiple causes of CVD morbidity and mortality. ${ }^{17} \mathrm{~A}$ study of 64 hemodialysis patients showed that there was a linear correlation between high UFR and all cardiovascular disease morbidity and mortality where UFR was $\geq$ $10 \mathrm{ml} /$ hour/ $\mathrm{kg}$ body weight has the highest risk. ${ }^{18}$

Excessive ultrafiltration during hemodialysis due to high IDWG will lead to activation of the sympathetic nervous system, activation of RAAS, increased cardiac output. The process with intradialytic ultrafiltration risks reducing the Relative Blood Volume (RBV) and Total Blood Volume (TBV). The decrease in RBV and TBV will decrease blood flow to the kidneys and stimulate renin release. Renin stimulates angiotensin I to angiotensin II causing vasoconstriction and aldosterone secretion. $^{2}$ Then vasoconstriction and aldosterone secretion will trigger an increase in intradialytic blood pressure.

Determination of the amount of ultrafiltration must be optimal to achieve normotensive conditions in hemodialysis patients. When hemodialysis UFG determination is determined to attract excess, the magnitude of the UFG may depend on the addition of the IDWG and the target dry weight of the patient ${ }^{9}$. High UFG can lead to intradialytic vascular resistance. Intradialytic vascular resistance surges remain implicated as the driving force for blood pressure increases. ${ }^{19}$
Previous studies on patients who had hypertension during hemodialysis showed dilatation of the heart. The patient had an increase in blood pressure on ultrafiltration. A study by Cirit et al concluded that paradoxical blood pressure increases with ultrafiltration usually due to overhydration and heart dilation..$^{20}$ Another study also by Chou et al proved that aggressive ultrafiltration can decrease the heart index and mean arterial pressure (MAP), these results support volume overload as the cause of the initial increase in MAP during ultrafiltration. ${ }^{21}$ This study also showed there was a correlation between ultrafiltration (UFG and UFR) with Intradialytic Mean Arterial Pressure $(\mathrm{p}=$ $0,016 \& p=0,034)$. The greater the UFG and UFR the higher the Intradialytic Mean Arterial Pressure $(r=0,227 \& r=0,200)$.

Previous research on seven patient undergoing hemodialysis showed that after the fluid was withdrawn a total of $2520 \pm$ $1698 \mathrm{cc}$ then $4.5 \pm 2.3 \%$ of the body fluid was withdrawn, the systolic heart function parameters were significantly increased to the maximum, arterial pressure increased from $107 \pm 5$ to $118 \pm 6 \mathrm{mmHg}$ with $\mathrm{p}$ $<0.027$. This increase in blood pressure was accompanied by an increase in the cardiac index (from $3.8 \pm 0.6$ to $4.8 \pm 1.1 \mathrm{~L} / \mathrm{min}$ / $\mathrm{m} 2, \mathrm{p}<0.027)$. This study also concluded that the increased blood pressure during ultrafiltration is due to an increase in cardiac output, mediated by volume overload. ${ }^{22}$ Fluid excess (overload) can also be associated with adherence to fluid intake. The findings of this study indicate that poor fluid adherence correlated with the incident of increasing intradialytic blood pressure. Hemodialysis patients should comply with the restriction of fluid intake. If the patient is not adherent, there is a higher risk of fluid overload and a higher risk of intradialytic hypertension.

Care must be taken to determine the amount of ultrafiltration during hemodialysis to keep blood pressure stable and the patient's condition safe. 
Determination of ultrafiltration that is not excessive and within the normal range will reduce the risk of an increase in intradialytic blood pressure. Determination of ultrafiltration during hemodialysis must be done carefully and precisely to prevent an increase in intradialytic blood pressure.

\section{CONCLUSION}

There is a relationship between ultrafiltrate and intradialytic blood pressure. The greater the ultrafiltration, the more the intradialytic blood pressure increases.

\section{ACKNOWLEDGMENTS}

Thanks to patients and nurses at two Hemodialysis Units in RS Roemani (Roemani Hospital) and RSUD Wongsonegoro (Wongsonegoro Hospital) Semarang.

\section{CONFLICTS OF INTEREST}

Neither of the authors has any conflicts of interest that would bias the findings presented here.

\section{REFERENCES}

1. Steddon S, Chesser A, Cunningham J, et al. Oxford handbook of nephrology and hypertension. Oxford University Press, 2014.

2. Hinkle JL and Cheever KH. Brunner and Suddarth's textbook of medical surgical nursing. In: Squazzo K, (ed.). 14th ed. Philadelphia: Wolters Kluwer, 2018, p. 6112.

3. Kallenbach JZ. Review of Hemodialysis for Nurses and Dialysis Personnel-E-Book. Elsevier Health Sciences, 2015.

4. Buren PNV, Kim C, Toto RD, et al. The prevalence of persistent intradialytic hypertension in a hemodialysis population with extended follow-up. Int J Artif Organs 2012; 35: 1031-1038. 2012/10/16. DOI: 10.5301/ijao.5000126.

5. Kandarini Y. Peran ultrafiltrasi terhadap hipertensi intradialitik dan hubungannya perubahan kadar: endothelin-1, asymmetric dimethylarginin dan nitric oxide. Disertasi, Universitas Airlangg, 2012.
6. Armiyati Y. Hipotensi dan hipertensi intradialisis pada Pasien Chronic Kidney Disease (CKD) saat menjalani hemodialisis di RS PKU Muhammadiyah Yogyakarta. In: Prosiding Seminar Nasional Unimus Semarang, 2012, pp.126-135.

7. Chazot $\mathrm{C}$ and Jean $\mathrm{G}$. Intradialytic hypertension: it is time to act. Nephron Clinical Practice 2010; 115: c182-c188.

8. Cheng Y, Li Y, Zhang F, et al. Interdialytic blood pressure variability and the risk of stroke in maintenance hemodialysis patients. 2020; 99.

9. NKF. Update of the KDOQI clinical practice guideline for hemodialysis adequacy. Minessota: National Kidney Foundation, 2015.

10. Agarwal $R$ and Light RP. Intradialytic hypertension is a marker of volume excess. Nephrology Dialysis Transplantation 2010; 25: 3355-3361.

11. Suwitra K. Penyakit Ginjal Kronik. In: Sudoyo AW, Setiyohadi B, Alwi I, et al. (eds) Buku Ajar Ilmu Penyakit Dalam. 6 ed. Jakarta: FK-UI, 2014, pp.570-573.

12. Locatelli F, Cavalli A and Tucci B. The growing problem of intradialytic hypertension. Nature Reviews Nephrology 2010; 6: 41.

13. Smeltzer SC, Bare BG, Hinkle JL, et al. Brunner \& Suddarth's textbook of medical-surgical nursing. 13th ed.: Lippincott Williams \& Wilkins, 2013.

14. Buren PNV and Inrig JK. Mechanisms and treatment of intradialytic hypertension. Blood purification 2016; 41: 188-193.

15. Zhang Y, Zhang X, Li J, et al. Dry-weight reduction improves intradialytic hypertension only in patients with high predialytic blood pressure. Blood Press Monit 2019; 24: 185-190. 2019/02/27.

DOI:

10.1097/MBP.0000000000000373.

16. Johan A. Hubungan besar ultrafiltrasi saat hemodialisis dengan kejadian peningkatan tekanan darah intradialitik pada pasien Gagal Ginjal Kronik. UNS, Surakarta, 2016.

17. Flythe JE, Kimmel SE and Brunelli SM. Rapid fluid removal during dialysis is associated with cardiovascular morbidity and mortality. Kidney international 2011; 79: 250-257.

18. Kim TW, Chang TI, Kim TH, et al. Association of ultrafiltration rate with mortality in incident hemodialysis patients. 2018; 139: 13-22.

19. Buren PNV. Pathophysiology and implications of intradialytic hypertension. Curr Opin Nephrol Hypertens 2017; 26: 303-310. 2017/04/12. DOI: $10.1097 / \mathrm{MNH} .0000000000000334$. 
20. Cirit M, Akcicek F, Terzioğlu E, et al. 'Paradoxical'rise in blood pressure during ultrafiltration in dialysis patients. Nephrology Dialysis Transplantation 1995; 10: 1417-1420.

21. Chou K-J, Lee P-T, Chen C-L, et al. Physiological changes during hemodialysis in patients with intradialysis hypertension. Kidney international 2006; 69: 1833-1838.

22. Gũnal A, Karaca I, Celiker H, et al. Paradoxical rise in blood pressure during ultrafiltration is caused by increased cardiac output. Journal of nephrology 2002; 15: 42-47. 